\title{
Assessment of Morphological Mutations and Genetic Components in MMS and EMS Induced Chilli Cultivars, NS 1101 and NS 1701DG
}

NAZARUL HASAN ( $\square$ nazarulpasha143@gmail.com )

Aligarh Muslim University Faculty of Life Sciences https://orcid.org/0000-0002-6123-4869

\section{Sana Choudhary}

Aligarh Muslim University Faculty of Life Sciences

Mehjabeen Jahan

Lovely Professional University

Nidhi Sharma

Aligarh Muslim University Faculty of Life Sciences

\section{Neha Naaz}

Aligarh Muslim University Faculty of Life Sciences

\section{Research Article}

Keywords: Chilli, Genetic Components, Mutagens, Mutants, Selection

Posted Date: September 10th, 2021

DOI: https://doi.org/10.21203/rs.3.rs-878724/v1

License: (9) This work is licensed under a Creative Commons Attribution 4.0 International License. Read Full License 


\title{
Assessment of Morphological Mutations and Genetic Components in MMS and EMS Induced Chilli Cultivars, NS 1101 and NS 1701DG
}

\section{Nazarul Hasan ${ }^{1 *}$ Sana Choudhary Mehjabeen Jahan Nidhi Sharma and Neha Naaz \\ Cytogenetic and Plant Breeding Laboratory, Aligarh Muslim University, Aligarh, India} (202002)

\begin{abstract}
A change in the genetic makeup of a plant is an essential prerequisite for the breeding programs and induce mutagenesis is an important approach to create the variations within crop germplasm. The main objective of this study is to find the mutants in chemically treated $\mathrm{M}_{2}$ chilli plant populations. Since, mutagenesis in chilli plants was induced through EMS and Cd to increase the genetic variability that results in thirteen mutant plants at $\mathrm{M}_{2}$ generation from the genetic background of chilli varieties NS 1101 and NS 1701 DG, respectively. Most of the mutant phenotypes observed felled within qualitative and quantitative characteristics the seven major categories including plant height, leaf shape, leaf color, branch, and flower color, fruits, 1000 seed weight, yield, and root length. The inter-population differences were carried out through analysis of variance of quantitative traits of chemically treated chilli populations. Results reflect increased mean value in quantitative traits that could validate the improvement over the parental lines. Fruit number and seed weight were the main priority traits in the selection of high yield plants and these quantitative traits have a strong association with the yield of the plant. Genetic variability induced by chemical mutagens in chilli can integrate into further chilli breeding programs as new crop germplasm with improved agronomic traits. Mutants selected from $0.2 \%$ treated chilli populations can be used to develop an efficient and fast crop variety of chilli with desirable traits. The present study about the genetic variability induced by chemical mutagenesis provides more opportunities to bring diversity in the genetic makeup of chilli plant for improvement of the desirable traits.
\end{abstract}

Keywords: Chilli, Genetic Components, Mutagens, Mutants, Selection 


\section{Introduction}

Chilli $(2 n=24)$ is a member of the genus Capsicum and the genus contains about 30 species of chilli. Five of them are cultivated at a larger scale throughout the world and cultivated species of this genus include Capsicum bacatum L., Capsicum annum L., Capsicum frutescens L. and Capsicum pubescens Ruiz and pavon. Pungent fruit (hot chilli) and non-pungent fruit (sweet chilli) are the two members of chilli grown widely. Besides most commonly used vegetables, spices and condiments, chilli have many adaptable and novel food non-food uses. The pungent varieties of chilli are used in small amounts and are mostly considered as a spice for seasoning and appetite stimulation while non-pungent are cooked as a vegetable and used for processing with the ingredients to impart the flavor in foods ("Veg. Prod. Pract."). Capsaicin obtaining from chilli extract possesses several nutritional and medicinal values as well. Capsaicin is a very complex form of capsaicinoids found in a variable amount in different varieties of chilli. Several workers reported that the fresh fruits of chilli contain high content of vitamin $\mathrm{C}$ as found in carrots (Osuna-García et al.; Bhattacharya et al.). Chilli is a very important crop of tropical and subtropical regions of the world and is cultivated on larger agricultural land (about 1.9 million hectares) in Asia, Africa, Southern Europe, and Central America (Vanitha et al.). India comprises about $42.2 \%$ (801, 600 hectare) of total agricultural land used in the production of chilli and produces $21.5 \%$ (1.5 million tons) chilli of the world (FAOSTAT. 2012). India has become a larger producer of chilli followed by China, Indonesia, Peru, Mexico and Thailand, Turkey, and tropical countries of Africa such as Ethiopia and Ghana. All states of India grow chilli as very essential crops and now chilli is a very important crop of the country and major producing states are Andhra Pradesh, Karnataka, Madhya Pradesh and Maharashtra (Post harvest profile of chilli 2009). Approximate $30 \%$ of total produced chilli of India is export as dry fruits to different Asian countries such as Sri Lanka, Bangladesh, Pakistan, Myanmar etc. (FAOSTAT. 2012).

Over a few decades, induce mutagenesis appeared as a more coherent approach and have a significant role in broadening the genetic base in several crops including chilli to overcome many obstacles situations in the genome. Induce mutagenesis is a highly recommended approach to spice crops for improvement in the chemical properties of these crops that are more difficult in conventional breeding. In spice crops new alleles as desirable traits have been developed through this approach in a short time without disturbing the basic structure of the genome; thereby possibility of sustain acceleration to generate the mutations toward desirable characters and 
resources with limited risk. Genetic variability determination in yield and yield associated traits in different genotypes of lentil plants will able to plants breeders to assess the extent of chemical mutagens to effects on yield (Laskar and Khan). Direct selection of yield-related traits can be deceptive due to several environmental factors that determine the yield of the crops ${ }^{[6]}$. Chemical compounds and yield-related traits in several crops are less affected in presence of chemical mutagens, hence, the selection of such traits can use to achieve new genotypes with better chemical compounds and high yield potential (Oladosu et al.). Heritability in genetic makeup provides much evidence about the regulation of gene expression in a gene of interest and about phenotype consistency that is used to predict the breeding value in crops (Zaman et al.). To date, some mutant varieties of chilli have been developed by using chemical mutagenesis. Further work on chilli needs to enhance agronomic and economic characters improvement by generating new alleles or novel genes through the development of more standard protocols of induced mutagenesis in breeding programs around the world, especially in India where the scope of agricultural rise is very high. The present study is carried out to find out the possibilities for generating desirable mutations in qualitative and quantitative characters of chilli cultivars by applying chemical mutagens. Similar to other crops chilli also show continuous variations in quantitative traits through polygenic effects of many independent genes with cumulative effects on characters expressivity. Different statistical methods were applied to detect the effects of different mutations in quantitative traits in chilli cultivars. Mutations of the traits were also assessed to understand the pattern of genetic inheritance and stability within M2 mutagenized populations. The main objective of the study was to the estimation of variation in genetic makeup and genetic inheritance pattern induced by different concentrations of chemical mutagens in qualitative and quantitative traits in the M2 generation of chilli cultivars. The study also was conducted to assess the genetic responses toward the different doses of mutagens, to evaluate the correlation among different agro-morphological characters with total yield per plant, and to identify the potential in mutated genotypes for the improvement the yield of the chilli crop through the breeding programs. Indian chilli possesses a wide range of genetic variability. Information on genetic variability in chilli plants was measured by the genetic coefficient of variation $(\mathrm{GCV})$, phenotypic coefficient of variation $(\mathrm{PCV})$, genetic heritability $\left(\mathrm{h}^{2}\right)$ and genetic advance (GA) for the individual qualitative and quantitative characters and through equilibrium distance over the characters. 


\section{Material and Methods}

The experimental material consists of two cultivars of $C$. annum provided by Agricultural University Ludhiana, Punjab, and is highly recommended for the agro-climatic zone of central India. The experimental material was planted in augmented RBD with 5 replication for each treatment at inter and intra row spacing was 45 and $15 \mathrm{~cm}$, respectively. Each genotype was grown in $9 \mathrm{~cm}$ long single pots established in the green house of the botany department of Aligarh Muslim University, Aligarh, India. The fresh and healthy presoaked (for 24hrs) seeds (moisture $10.5 \%$ ) of both cultivars of chilli were treated (6hrs) with different concentrations (0.01\% to $1.0 \%$ EMS and MMS). The first effects of different concentrations of both mutagens were determined based on lethal dose $\left(\mathrm{LD}_{50}\right)$ value in seed germination and plant survival. 135 seeds for each treatment were sown as five replicate and irrigates and weeding, and grown under protective measures following the randomized complete block design (RCBD). Self-pollinated fertile plants were selected from the $\mathrm{M}_{1}$ generation and 15 healthy seeds of each treatment were sown to rise the $\mathrm{M}_{2}$ generation. Data of quantitative characters were collected for statistical analysis and the mean value of each treatment was used to assess the genetic diversity and degree of divergence within mutant populations.

\section{Morphological Data Record on Plant Basis}

1. Plant Height (PH):- Average plant height was taken randomly from each treated plant population. The height of the plant was measured from the ground part to the top of the plant at harvesting time.

2. Branch per Plant (BP):- Average number of a branch of the main stem was taken randomly from each treatment.

3. Fruit per Plant (FP):- Fruits were collected from each treated plant and counted randomly as the average number.

4. 1000 Seed Weight:- Weight of 1000 seeds was taken in grams from randomly selected fruit by using electric balance.

5. Fresh Yield per Plant (FYP):- The fresh fruits were collected from 65 days old randomly selected chilli plant in each treatment and weight is taken in grams.

6. Dry yield per Plant (DYP):- Dry fruits were collected from randomly selected chilli plants at the time of harvesting and weight was also taken in grams by using electric balance. 
7. Root Length $(\mathrm{RL})$ :- Root length $(\mathrm{cm})$ was measured for the underground part randomly selected plants in each treatment.

8. Days to $90 \%$ Maturity (DM):- Days were counted as a number from the sowing date of seeds to the days at which $90 \%$ maturity reached physiological maturity. It is the time when $90 \%$ of fruits change their color into dark red and become dry. The growing time of the plant was calculated as a period from seed sowing to seed maturity.

9. Fruit Length (FL):- The length of fresh fruit was measured in the randomly selected plant from each treatment.

\section{Statistical Analysis}

Statistical analysis was carried out on data obtained from seven quantitative characters of chilli like days to flower maturation, plant height, and branch per plant, fruit per plant, 1000 seeds weight, fresh yield per plant, and dry yield per plant in M2 generation.

Detailed statistical (mean value) is associated with different characters considered in this investigation across all the concentrations of mutagens that were calculated in M2 generation. One-way analysis of variance (One-Way-Anova) was carried out to estimate mutagenic effects between observations and, to assess the differences between the mean value of various treatments and the control population. Statistical significant ANOVA was performed by following the Duncan Multiple Range Test (DMRT) and character association was done by Pearson's correlation coefficient (r) test. All the statistical data analysis was carried out under the International business Machine Cooperation Statistical Package for Social Science (IBM SPSS 20.0).

\section{Estimation of component variance}

The genotypic variance of quantitative characters was calculated by using a formula given, (Burton and DeVane) as follows:

Genotypic coefficient variance $(\mathrm{GCV})=\frac{\sqrt{\sigma 2 G}}{X} \times 100$

Where,

$\sigma^{2} \mathrm{G}=$ genotypic variance $=\mathrm{MSG}-\mathrm{MSE} / \mathrm{r}$; (MSG is the estimation of the mean square of tested accession, MSE is the estimation of the mean square of error and $r$ represents to replication number). 


\section{Broad sense heritability $\left(h^{2} b s\right)$}

The broad-sense heritability of the characters was computed by adopting (Allard et al. 2011) Allard, 1990 formula.

$$
\mathrm{h}^{2} \mathrm{bs}=\sigma^{2} \mathrm{G} / \sigma^{2} \mathrm{P}
$$

Where,

$\sigma^{2} \mathrm{G}$ is genotypic variance and $\sigma^{2} \mathrm{P}$ is phenotypic variance.

The range of heritability has been classified and suggested by Jhonson and Wiechem in 1960

$$
\text { Low }<40 \% \text {, Medium:High 60-80\%, Very high }>80
$$

\section{Genetic Advance (GA)}

Genetic advance for selection intensity $(\mathrm{k})$ of traits was estimated at $5 \%$ by using a formula suggested by (Allard et al. 2011) and Jhonson et al. (1955b).

$$
\mathrm{GA}=\frac{k \cdot \sigma p \cdot h^{2} b s}{X} X 100
$$

Where,

GA is genetic advance under trait selection; $\sigma \mathrm{h}$ is phenotypic standard deviation; $\mathrm{h}^{2}$ is broad-sense heritability and $\mathrm{k}$ is selection differential $(\mathrm{k}=2.06$ at $5 \%$ selection intensity). Range of genetic advance has also been suggested by Jhonson et al. 1955b

$$
\text { Low }<10 \% \text { : Moderate 10-20\%: High }>20 \%
$$

\section{Character Association}

Trait correlation and trait significance were determined by SPSS software and phenotypic and genotypic correlation yield and yield associated traits were estimated by using the method described by Kasssiani and Saleh in 2010 from corresponding variance and component variance as follows;

$$
\begin{aligned}
& \text { Phenotypic correlation coefficient } \mathrm{rpxy}=\frac{p \operatorname{covx} \cdot y}{\sqrt{\mathrm{d} 2 \mathrm{px} * \mathrm{~d} 2 \mathrm{py}}} \\
& \text { Genotypic correlation coefficient } \operatorname{rgxy}=\frac{g \operatorname{covx} \cdot y}{\sqrt{\mathrm{d} 2 \mathrm{gx} * \mathrm{~d} 2 \mathrm{gy}}}
\end{aligned}
$$

Where,

rpxy is a phenotypic correlation coefficient between character $\mathrm{X}$ and $\mathrm{Y}$; rgxy is a genotypic correlation coefficient between character $\mathrm{X}$ and $\mathrm{Y}$; pcov $\mathrm{x} . \mathrm{y}$ and gcov $\mathrm{x} . \mathrm{y}$ are 
phenotypic and genotypic covariance between $\mathrm{X}$ and $\mathrm{Y}$, respectively; $\sigma^{2} \mathrm{p}$ and $\sigma^{2} \mathrm{~g}$ are phenotypic and genotypic variance between characters $\mathrm{X}$ and $\mathrm{Y}$. The significant value of phenotypic correlation is calculated by using a t-test

$$
\mathrm{t}=\frac{r p}{S E(r p}
$$

Where,

$\mathrm{rp}$ is a phenotypic correlation; $\mathrm{SE}(\mathrm{rp})$ is the standard error of phenotypic correlation. The value of $\mathrm{SE}(\mathrm{rp})$ is calculated by using a formula of Sharma, 1998

$$
\mathrm{SE}_{(\mathrm{rp})}=\sqrt{\frac{(1-2 r p)}{(n-2-}}
$$

Where,

$\mathrm{SE}$ is a standard error at the genotypic level and $\mathrm{n}$ is the number of tested genotypes. Its significant value is calculated by using a formula described (Robertson).

$$
\mathrm{t}=\frac{\operatorname{rgxy}}{\operatorname{SErgxy}}
$$

$\mathrm{t}$ value is compared with tabulated $\mathrm{t}$ value at (n-2) degree of freedom at $5 \%$ significant level.

$$
\text { SErgxy }=\sqrt{\frac{\left(1-r^{2} g r y\right)}{\left(h^{2} x \cdot h^{2} y\right)}}
$$

Where,

$\mathrm{h}^{2} \mathrm{X}$ is the heritability of trait $\mathrm{X}$ and $\mathrm{h}^{2} \mathrm{y}$ is the heritability of trait $\mathrm{Y}$

\section{Multivariate Analysis}

The average linkage method for hierarchical clustering with squared Euclidian distance was done by SPSS software. Quantitative data was standardized for to zero mean value of one before to prepare clusters for removing any partial error that can arise due to different measurement scales. Cluster distance and square Euclidian distance were calculated by using an average method to estimate the genotypes are closely related or distantly related. Genetic distance between clusters was calculated by using a formula suggested by Mahala Nobis, 1936.

$$
D^{2} i j=(x i-x j)^{1}(x i-x j)
$$

Where,

$\mathrm{D}^{2} \mathrm{ij}$ is the distance between any two groups $\mathrm{i}(\mathrm{xi})$ and $\mathrm{j}(\mathrm{xj})$ vector mean of $\mathrm{S}$. 


\section{Principle Component Analysis (PCA)}

PCA for 9 standardized quantitative characters was computed through SPSS software to identify the most significant trait contribute variation among observed accession and accession with a greater value of PCA is considered as significant. PCA value was calculated by the following formula given by Johnson and Wichern in 1998.

$$
\mathrm{Pcl}=\mathrm{b} 11(\mathrm{z} 1)+\mathrm{b} 12-\mathrm{blp}(\mathrm{xp})
$$

Where,

Pcl is the subject's score for principal component 1 (the first component extracted); bip is regression coefficient for observed variable $\mathrm{p}$ used in the creation of component 1; $x p$ is subject's score on the observed variable.

\section{Results}

\section{Morphological Mutants}

The ten concentrations of two chemical mutagens were taken to induce the qualitative and quantitative diversity in two different cultivars of chilli, one for one cultivar. The fresh and healthy seeds of both cultivars were treated with different concentrations for 6 hrs following presoaking treatment with distilled water for $18 \mathrm{hrs}$. The five characters with different accessions were grouped by morph-types that indicate the existence of several duplicates in both cultivars (Table 1). In this research, many qualitative variables were studies and the frequency of distribution was summarized based on morphological characterization. These qualitative variables were observed in 9 weeks old plants of each treatment. Different accessions of plant height were recorded to $47.33-72.00 \%$ for both tall and dwarf plants and stem color varies from pale yellow to light green and mutations frequency of both colors was measured to 20.50$51.47 \%$. The branching pattern was different for each accession in which it varied from 16 to 9 per plant and 30.06-35.00\% and 29.00-30.21\% mutation frequency was found. The leaf morphology also was studied and observed with various accessions in which 12.00-18.50\% accession was having round and lanceolate leaf shapes. The color of the leaf was observed different for various color accessions, 15.14-18.00\% accessions were reported to having Chlorina, $18.00-20.22 \%$ having Xantha phenotype, almost the same 8.00-9.00\% albino phenotypes were observed in both cultivars. The color of the flower in both cultivars treated different chemical mutagens observed to vary in different accessions. High mutation frequencies in light whitish flowers were recorded $23.78-28.18 \%$ and the lowest proportion of flower color was measured for the violet color which reached only $2.00-7.25 \%$ in both the cultivars. The fruit 
morphology of chilli plants is the most important characteristic concerning their pungency and hotness. The variation in fruit color was observed from the early-maturing stage to the time of harvesting of chilli crop. At the early maturing stage $14.55 \%$ of fruit have a light yellow color, $15.25-10.50 \%$ have dark red color while other $8.33-4.12 \%$ have light and dark green color fruit. The size of the fruit varies in each accession in which one accession (5-2 cm long) has a 13.33$44.29 \%$ proportion in all accessions. The root accessions were observed to vary for different treatments in which $22.19-23.36 \%$ root accessions have $13-4 \mathrm{~cm}$ long while $14.00-14.9 \%$ accession have $12-3 \mathrm{~cm}$ long roots. The existence of significant variations in phenotypes was detected for all the accessions in qualitative traits such as plant habit, leaf morphology, flower, fruit, and roots (Table 1 and Figure 1-6).

\section{Quantitative Diversity}

Quantitative characters associated with yield directly or indirectly are plant height, branch per plant, fruit per plant, 1000 seed weight, fresh yield weight, dry yield weight, and root length that have remarkable importance in chilli breeding. However, these quantitative characters of both cultivars were chosen to select the improved genotypes with high yielding capacity. Significant levels $(\mathrm{p} \leq 0.01)$ for mean value and variations were recorded by applying analysis of variance (ANOVA) and the least significant differences (LSD) were recorded through Duncan's Multiple Range Test (DMRT). ANOVA revealed that variations and growth parameters were varied for accessions to their corresponding traits. Maximum plant height, branch per plant, fruit per plant, 1000 seed weight, dry and fresh yield were observed at $0.01 \%$ concentration of MMS and $0.20 \%$ of EMS, respectively. Maximum reduction in all characters was recorded at higher concentrations $(1.0 \%$ and $100 \mathrm{ppm})$ of both chemical mutagens. The maximum mean value in plant height was recorded to be $79.338 \mathrm{~cm}$ and $79.67 \mathrm{~cm}$ long at $0.01 \%$ concentrations of EMS and MMS, respectively, while the minimum mean value in plant height was observed to be $61.17 \mathrm{~cm}$ and $63.13 \mathrm{~cm}$ long at the highest concentrations $1.0 \%$ of both chemical mutagens in compare to control plants. The number of branches per plant was found to be 11.67 at $0.01 \%$ and $0.20 \%$ concentrations of EMS and 12.33 branches per plant was observed at $0.01 \%$ concentration of MMS. The number of fruit per plant enhanced at higher concentrations of $\mathrm{Cd}$ and EMS and the maximum mean value was found to be $79.00 \mathrm{~cm}(0.01 \% \mathrm{EMS})$ for NS $1701 \mathrm{DG}$ and 80.33 for NS $1101(0.20 \%$ MMS $)$ cultivar. Seed weight was recorded to a maximum $7.08 \mathrm{~g}$ and a minimum $5.43 \mathrm{~g}$ at $0.01 \%$ and $1.00 \%$ concentration of EMS, respectively; while at $0.1 \%$ 
concentration of MMS it was recorded to be $6.97 \mathrm{~g}$. Other yield contributing traits such as fresh yield per plant was measured to be maximum 205.83g at 10ppm concentration of EMS (NS 1701 DG); in NS 1001 this value was found to be $202.00 \mathrm{~g}$ at $0.01 \%$ concentration of MMS. The highest significant reduction in dry yield per plant was observed at a higher concentration of both chemical mutagens. $27.36 \mathrm{gm}$ and $26.5 \mathrm{gm}$ dry yield per plant was recorded at $0.1 \%$ and $0.2 \%$ MMS concentrations which are more than $25.85 \mathrm{~g}$ that was calculated at $0.01 \%$ concentration. In EMS treated plant dry yield per plant was recorded to a maximum of $29.08 \mathrm{~g}$ in the control population, while the highest reduction dry yield per plant was reported to $18.67 \mathrm{~g}$ at $1.00 \mathrm{MMS}$ concentration. $12.33 \mathrm{~cm}$ long root was seen in $0.10 \% \mathrm{EMS}$ concentration that was more than $11.67 \mathrm{~cm}$ long root of $0.01 \%$ EMS treated chilli population and maximum reduced $6.5 \mathrm{~cm}$ long root was observed at $0.10 \%$ concentration of EMS. At $0.1 \%, 0.2 \%, 0.3 \%, 0.4 \%, 0.5 \%$ and $0.6 \%$ concentration of MMS, the root length observed to be maximum than $0.01 \%$ concentration. The maximum days to flowering was recorded to be 65.71 days and 60.75 days at higher concentrations of both chemical mutagens, while these limit of time to flower reduced to the maximum at higher concentration (Table $2 \& 3$ ).

\section{Genetic Diversity}

The magnitude of genetic diversity of a plant species is used to understand and improvement of genotypes for further study during plant breeding. Different genotypic parameters were taken for all seven characters in both chemically treated cultivars. Collected data were subjected to ANOVA for RBD by using GenStat Release 10.3 Discovery Edition (PC/Window; VSN Internation Hemel Hempstead, Hertfordshire, UK) to assess the genetic diversity between different genotypes. Mean value of all genotypes used separately to calculate different genotypic parameters such as genotypic coefficient of variance (GCV), broad-sense heritability ( $h^{2} b s$ ), genetic advance, and correlation coefficient (r). Hierarchical cluster and principle component analysis were also carried out with GenStat Release Discovery Edition to show high discriminatory traits and the level of relationship between genotypes. Genotypic coefficient of variance or GCV provides a measure of genetic diversity that exists in various quantitative traits. High GCV was obtained $8.54 \%$ for the fruit per plant at $0.40 \%$ concentration of EMS in NS 1701 DG cultivar. Maximum GCV value $8.57 \%$ for fruit per plant in NS 1101 was obtained at $0.4 \%$ concentration of MMS treated population and lowest value $0.33 \%$ at $0.3 \%$ concentration. GCV $2.98 \%$ for plant height was observed to be highest at 1.00\% concentration of EMS and the 
lowest GCV was recorded at $0.20 \%$ in NS 1701 DG cultivar. In the case of NS 1101 cultivar, it was observed maximum to $3.73 \%$ at $0.4 \%$ and lowest $0.22 \%$ at $0.7 \%$ concentration of MMS. 1000 seed weight shows a high GCV value (15.44) at 90ppm concentration and the lowest value at 0.11 at $70 \mathrm{ppm}$ concentration. Fresh weight per plant maximum value of GCV was observed to be $46.95 \%$ at $0.50 \%$ and lowest GCV value $0.3 \%$ at $0.60 \%$ EMS. Root length in EMS treated population has highest GCV value to be $7.72 \%$ at $0.7 \%$ concentration and lowest GCV was to be $0.55 \%$ at $0.2 \%$ concentration. In the case of EMS treated chilli population has maximum GCV to $21.20 \%$ at $1.00 \%$ and lowest at $0.90 \%$ in comparison to the control population (Table $2 \& 3$ ).

\section{Broad Sense Heritability $\left(h^{2} b s\right)$}

Estimation of genetic heritability gives an insight into the extent of control the expression of a particular gene and phenotypic reliability for predicting the breeding value of the trait. Broad sense heritability $\left(\mathrm{h}^{2} \mathrm{bs}\right)$ indicates only whether or not there is sufficient genetic variation in a population that population will or will not respond to selection pressure. Maximum $\mathrm{h}^{2} \mathrm{bs}$ was recorded in all treatments of traits in both chemically treated cultivars except some treatments. Maximum heritability for plant height was recorded to $80.92 \%$ at $0.01 \%$ concentration and lowest heritability $13.13 \%$ at $0.50 \%$ concentration of EMS. The highest broad-sense heritability such as $72.68 \%, 80.58,82.92 \%, 85.48 \%, 83.62 \%$, and $81.27 \%$ was recorded at a variable concentration of $\mathrm{Cd}$ for branch per plant, fruit per plant, thousand seed weight, fresh yield per plant, dry yield per plant and root length. Unlike, the lowest heritability in these different traits was calculated at a variable concentration of EMS. In MMS treated chilli population highest heritability includes-75.52\%,81.65\%, 80.94\%, 93.51\%, 91.00\%, 83.00\% and $75.18 \%$ were recorded at variable concentration of MMS. Similarly lowest broad-sense heritability (such as $5.16 \%, 9.49 \%, 11.47 \%, 13.07 \%, 17.96 \%, 19.01 \%$, and $21.37 \%$ ) was observed in various concentrations of both EMS and Cd treatments and their respective control, depicted in table 2 and 3 .

\section{Genetic Advance (GA)}

In the present experimental study, genetic heritability coupled with genetic advance was recorded for different quantitative traits induced by MMS and EMS. The highest genetic advance was recorded for thousand seed weight in NS 1701DG cultivar, while the lowest value of GA was shown in fruit per plant. In MMS treated population highest value of genetic advance was 
recorded in thousand seed weight as in EMS treated population, whereas the lowest value of genetic advance was recorded in fresh weight per plant in NS 1101 cultivar.

\section{Character Association}

A desirable improved trait can be obtained through indirect selection vial other traits which are more heritable and easier to select. This strategy of selection requires better perception about the interrelationship of traits among themselves and within the target trait. Results of characters association of in M2 population have represented in the table and shown that correlation coefficient varies for each trait. Correlation coefficient study of both treated cultivars shows a relationship between traits. In cultivar, NS 1101 fresh yield per plant shows a significant positive correlation with thousand seed weight and fertile branches per plant, unlike, flower length has a significant positive correlation with day to flowers. In cultivar, NS 1701DG fresh yield per plant showed a significant and positive correlation with the fertile branches and thousand seed weight, while fruit length has a significant and positive correlation with dry yield per plant. Results should be recommended for the selection of quantitative traits in treated chilli population can be done by the screening of high yielding mutant plants (Table 4).

\section{Multivariate Analysis}

Diversity in genetic material plays a very important role in the improvement of a crop, especially in the selection of parental lines for hybridization. Several workers reported that crossing between different members of the parental line showing genetic diversity in quantitative characters results in desirable segregation in subsequent selection.

\section{Cluster Analysis}

Analysis of genetic diversity between or within a population is a standard to select the parental line during which degree of genetic diversity among observable genotypes demonstrate. Cluster analysis must provide a very strong clue about the nature and degree of divergence that are more notable things for the selection of the expected genotypes. This study was carried out to assess the Euclidean distance by using standardized quantitative data and UPGMA Dendrograms were constructed by using the mean value of nine genotypes of both the cultivars. The number of clusters determined was three for each cultivar and the phylogenic relationship was shown on basis of Dendrograms. Cluster pattern of Dendrograms of different populations showed dissimilarity between clusters and hierarchical categorization among and within clusters. A large number of plants were mutated at $0.1 \%$ and $0.5 \%$ concentration of MMS in NS 1101 cultivars in 
comparison to their respective controls. The cluster size was recorded to 1-8 for NS 1701DG and 1-5 for NS 1101 cultivars. It was observed that the control population did not form an

independent cluster and shown some genetic variation in quantitative traits having certain similarities with traits induced by chemical mutagens. In EMS treated populations, maximum numbers along with control were recorded in cluster-I, while maximum numbers in MMS treated populations were recorded from cluster-III. Inter-population matrix revealed maximum Square Euclidean distance was found at 1.0\% (7.3) and 100ppm (8.5) concentration of MMS and EMS, respectively, while lowest Squared Euclidean distance was found to be 0.22 in NS 1101 and 0.077 in NS $1701 \mathrm{DG}$ at $0.1 \%$ and $5 \mathrm{ppm}$ concentration, respectively. Cluster I was found to be the highest mean value $(79.43$ and $77.07 \mathrm{~cm})$ for plant height in both cultivars, while the mean value $(75.31$ and $66.50 \mathrm{~cm})$ in cluster III is more than cluster II. Similar results were found for thousand seed weight, where the highest mean value $(6.97 \mathrm{~g}$ and $6.69 \mathrm{~g})$ was found in cluster I, while the mean value $(6.46 \mathrm{~g}$ and 5.87$)$ of cluster III for 1000 seed weight was more than the cluster II. Hence, populations that come under this cluster analysis could be screened for the selection of high-yielding plants (Figure 7 and Table 5, 6).

\section{Principle Component Analysis (PCA)}

Principle component analysis is used at a larger scale in crop sciences for the sorting of characters and grouping of accessions. In PCI large group with a positive load is plant height (0.926 and 0.991) whereas the smallest group with a positive load is for flower $(0.128$ and 0.563). The largest group with positive load (0.925 and 0.826) and negative load (-0.328) was found in PCII for flowers. Likely, PCII with a negative load (-0.170) was found for dry yield per plant. Two extracted principle components PCI and PCII of original data have shown value more than once in the latent root (Eigenvalue), thereby estimating $91 \%$ and $95 \%$ variations in crops. In this study PCI shown about 82\% and 87.57\% variability in NS 1101 and NS 1701DG, respectively and PCII shows the variability of about 9.5\% in NS 1101 and $8.12 \%$ in NS 1701 DG that are unrelated and not summarized by PCI. Hence, the total variation in original data of mean is broken into independent components and cumulative variability was recorded to $91.5 \%$ for NS 1101 and 95.6\% for NS 1701DG, respectively. Principle component analysis revealed yield and yield contributing characters showed more diversity in the treated population. Hence, yield and yield contributing traits were considered that they respond desirably to various mutagenic treatments for the possible selection of mutant plants. The distribution pattern also indicates to 
the existence of significant variability between and within mutagenized populations for quantitative traits (Table 7).

\section{DISCUSSION Qualitative traits}

In the present study genetic diversity has been estimated in qualitative traits by proper selection of mutant plants based on their morphology. Different flower mutants were observed in the various mutagenized population of crop plants having a variable number of sepals, petals, color, anthers, and ovule (De Haro-Bailón and Del Rio), carpel number and flower morphology, and different color flowers (Dela et al.). The genotypic potential of floral mutants maintains the trait purity in variety for the next generation (Devi and Mullainathan). Changes in floral organs are due to alteration in genetic material which results in loss of function of the gene. Mutation frequency in flowers was reported to increase with increasing concentration of chemical or physical mutagens (Nishihara and Nakatsuka). Improved genotypes from a mutagenized population were selected due to the estimation of significant variations with high magnitude among accessions (Caillei et al.). Several workers reported a significant level of dissimilarity in quantitative traits of crop plants including chilli crop (Abu and Buah)(Usman et al. $)^{[19]}$. In the present study, nine quantitative characters were taken and these characters shown significant variations in each treatment. Different workers found similar observations that preferred to farmers for improvement the genotypes in compared to others provides advantages during harvesting of crops. The occurrence of variations in yield and yield-related traits suggest significant selection could be made to improve the yield and other traits under chemical treatments. Assessment of genetic diversity in qualitative traits has several limitations such as chromosomal abnormality and environmental factors, on qualitative expression, and the qualitative data is helpful in the primary assessment of genetic diversity in pulses and provides the information required to assess available germplasm (Choudhary et al.). Qualitative traits play a very important role in the grouping of genetic resources in chilli and are also useful for plant breeders for the improvement in the existing germplasm of breeding plant population through the introduction of desirable mutations in a particular trait (Zaman et al.) (Thirumala Rao) (Mishra et al.) (Fechtali and Nabloussi). In this research data of genetic variability of nine genotypes is helpful in possible selection and improvement. Workers reported that significant variation in 
growth, yield, and yield-related traits in different genotypes of pepper crop (Sood et al.) (Saha et al.), and significant variability in day to flowering among various genotypes of plants (Craufurd and Wheeler).

\section{Genotypic Components of Variance (GCV, $\mathrm{h}^{2}$, and GA)}

In this study analysis of variance revealed that high significant differences $(p<0.01)$ among nine tested genotypes show variability. The significance value of GCV, $\mathrm{h}^{2}$, and GA were recorded variables for each concentration of both mutagens. Genotypic coefficient of variance provides information about variability in genetic makeup present in all quantitative characters in a treated population of chilli, but not possible to determine the variations were heritable from the genotypic coefficient of variance. Genotypic coefficient of variance with broad-sense heritability estimate could give the best picture of the amount of advance to be expected from selection (Burton and DeVane). Thus, the heritable portion of the variation could be more useful with help of heritability estimates. The value of the genotypic coefficient of variance was represented in percent and the highest value of GCV was recorded in plant height, fruit per plant, 1000 seed weight, and fresh yield per plant at $0.01 \%, 0.40 \%, 0.90$ EMS concentrations, whereas in MMS treated populations high GCV was observed at $0.80 \%, 0.40 \%, 0.60 \%$ concentrations. The high value of the genetic coefficient of variance suggested that it has a great role in inducing variability at a genetic level. Several workers were reported that quantitative traits like yield in sorghum plants showed a high value of the genetic coefficient of variance and possess high potential to improve the plants and has advantages in simple selection for yield as compared to its components under study. Several workers reported a high value of the genotypic coefficient of variance for plant height, fruit per plant, fruit length, and yield per plant in different crops (Datta and Jana) (Raturi et al.) (Mahajan et al.) (Kumar et al.). Heritability estimate has great importance in phenotypic reliability of traits and helps the breeders to make selection easy for traits wherein variability is high (Akinwale et al.). Alone heritability does not provide any idea about genetic improvement in individual genotypes, and hence knowledge of the heritability amount of genotype is coupled with the genetic advance (GA) to assess the genetic diversity of the traits. Genetic advance is mostly used to predict the expected genetic gain in genotypes from one cycle of selection (MISHRA et al.). In the present study, the value of percent genetic heritability ( $\mathrm{h}^{2} \mathrm{bs}$ ) and percent genetic advance (GA) were reported to vary for each trait at a variable concentration of EMS and MMS. High genetic advance is mainly associated with high 
heritability that indicates additive gene action, due to which traits selection become more effective (Akinwale et al.). Similar results of heritability were also reported in plant height, branch per plant, fruit per plant, and days to flowering in radish plant (Kaushik et al.). In our study, analysis of variance using genetic components indicates significant variations in all seven quantitative traits in different mutagenized chilli populations in comparison to their respective controls that confirms the possibility of improvement of traits in subsequent generations through a selection process. Several workers reported that the value of genetic heritability and genetic advance are independent to each other for most quantitative traits in treated populations that indicate high heritability and large genetic advance could not be expected always (Najeeb et al.)(OSMAN et al.). Therefore, heritability in association with genetic advances would assist in effective prediction for the selection of elite genotypes in plant breeding programs (Ogunniyan and Olakojo). The results of quantitative traits in cultivar NS 1101 responded desirably to most agro-morphological traits in first four treatments of MMS, whereas cultivar NS 1701DG responded similarly in first two treatment of EMS. The sensitivity of genetic material toward chemical mutagens was found to be high for EMS (NS 1701DG) in compare to MMS (NS 1101). Therefore EMS has more deleterious effects on DNA than MMS, so more numbers of mutation are possible in MMS, which may result as negative impact. In present study, high variability range in yield and yield attributed traits such as branch per plant, fruit per plant, 1000 seed weight in M2 generation of both cultivars has confirmed the possibilities of selection of improve genotypes in subsequent generations.

\section{Multivariate Analysis}

Gene distance between species is a measurement of genetic diversity between or within the populations and it also measures the time of divergence from a common ancestor or counted as a degree of divergence (Beaumont et al.). Phenotypic characterization and effective assessment of unrelated traits in mutant populations with their respective parents is a very important part of mutation breeding. Statistical algorithms multivariate analysis applies in mutation breeding to assess the genetic diversity in a mutant population. The workers were suggested such a statistical analysis approach to characterize the genetic diversity in a mutant population of crop plants (Muduli and Misra). Principle component analysis and cluster analysis are a very important part of multivariate analysis and use simultaneously in the evaluation of morphological, chemical, and molecular data. Both statistical techniques are used to sorting interrelated populations of 
crops during plant breeding programs (Malek et al.) (Ahmad et al.). In this study, multivariate analysis was taken to assess the genetic diversity in chemical-induced chilli populations with their respective control population. Chemical induce variability was expressed in percent for yield and yield associated traits to find out the possibility of selection of novel traits. Generally, multivariate analysis is a data reductive technique applied in breeding populations for detection of the accuracy in improved mutants, therefore, cluster analysis and principle component analysis were used to simplify the complex data during the selection process. Cluster analysis was carried out to grouping of populations on basis of responses to nine morphological markers i.e., based on distance and proximity, and principle component analysis was carried out to make the groups in morphological markers on basis of responses to variations or correlations.

\section{Correlation Study}

The degree of the linear relationship between the traits considered the function of selection, genetic linkage, and pleiotropy (Sakai and Suzuki). The study was performed to characterize the 11 chemically treated chilli population of each cultivar on basis of a significant correlation between nine quantitative traits. A high significant correlation value with a positive effect for yield was obtained. The strength of correlation for traits was observed to be plant height $>$ fresh yield per plants $>$ thousand seed weight $>$ fruit length $>$ day to flower while the correlation in cultivar NS 1701DG was observed to differ i.e., plant height $>$ root length $>$ fresh yield per plant $>$ fertile branch $>$ thousand seed weight. The yield of the plant was significantly and positively associated with fruit per plant, 1000 seed weight, and root length. This correlation between traits could contribute to food quantity synthesis at the time of photosynthesis or physiological activities of the plant, so it has a direct effect on yield traits. Several reports are available confirming selection in inter-correlated yield-associated traits will enhance the yield of the grains. Thus the selection of the quantitative traits should also give great importance along with yield and yield associated traits at the time mutation breeding experiments on crop cultivars (Muduli and Misra) (Amin et al.).

\section{Cluster Analysis}

Nine genotypes of each cultivar were grouped into three clusters of quantitative traits at a distance coefficient of 1.26 showing diversity level among genotypes. In $\mathrm{Cd}$ treated population cluster group-1 contains eight genotypes, group-II showing only one genotype, and group-III has 
four genotypes. In EMS treated population cluster group-I contains four genotypes; cluster group-II has three genotypes and cluster group-III contains five genotypes. Distance between inter-clusters is very important to determine the parental line in crossbreeding programs and a high distance between clusters will show high genetic variability in segregating generations. Ullah et al. 2012 recommend high contributing clusters that divergence be supposed to greater importance to select the cluster type for the further selection process and parental line in succeeding generations. In mutation breeding, the most diverse cluster along with the parental cluster can be used effectively for the selection of elite mutants from subsequent generations. In the present study, cluster analysis has applied to divide the mutants into different clusters, which were close to their respective control or were deviate significantly from their respective control in this manner revealed heterogeneous populations induced by mutagenic treatment used. The members of a cluster are genetically close to each other and members of different clusters shown dissimilarities in genotypes of the first cluster.

\section{Principle Component Analysis}

Principle component analysis yields an eigenvalue for each principle component axis to account for the mutations present among genotypes. Principle component analysis is justifying the data obtained from cluster analysis. In the present experimental study, PCA in yield contributing traits of M2 generations was performed for characterization of traits into different phenotypes of mutant chilli populations, and to identify the novel traits helpful to propagate the M3 generation. The yield and fruit number per plant are the major contributors to genetic divergence within the chilli population. Therefore, these quantitative traits are more favorable to further selection process in a subsequent generation which may lead to more distinct yield mutants. The hybridization between high yield mutant and fruit per plant may be more effective for the selection of novel improved mutant in next-generation (Ahmadizadeh and Felenji). Principle component analysis has highly recommended in an effective selection of elite traits for further breeding study (O. et al.).

\section{Conclusion}

In the present study all quantitative traits of both cultivars of chilli show a high level of genetic variability and results revealed that genotypes of yield and other yield contributing traits exhibit better performance, therefore, these genotypes should be useful in breeding programs. The 
highest genetic coefficient of variance was noted in plant height, branch per plant, and thousand seed weight and root length. Character association studies revealed that the yield in each cultivar is significant and positively correlated with branch per plant, fruit per plant, thousand seed weight. Maximum genetic heritability was recorded for root length, branch per plant, thousand seed weight of both cultivars. Genetic heritability in association with genetic advance was recorded to be high in root length, days to flowers, and fruit per plant. Genetic assessments on chemically induced mutations in yield contributing traits show significant divergence in interpopulations. Investigations are evident that the selection of mutants may be more effective by coupling the genetic heritability with genetic advance. Gene action is recommended for further study to select the yield contributing traits, hence, chemical mutagens have a very important role in the improvement of quantitative traits in crop breeding programs. Stability in genetic heritability should be analyzed and improved mutants should be hybridizing to produce the elite genotypes in the next generations of chilli cultivars.

\section{Acknowledgment}

The authors are thankful to the head of the cytogenetic and plant breeding lab for guiding us, and the chairman of the botany department of Aligarh Muslim University, Aligarh, India for providing necessary facilities during the study of the research.

\section{Funding}

Not applicable

\section{Conflict of interest}

The author declares no conflict of interest in this research

\section{Consent of research}

Not applicable 


\section{References}

Abu, Huudu Bampuori, and Samuel Saaka Jeduah Buah. "Characterization of Bambara Groundnut Landraces and Their Evaluation by Farmers in the Upper West Region of Ghana." Journal of Developments in Sustainable Agriculture, vol. 6, no. 1, Agricultural and Forestry Research Center, University of Tsukuba, 2011, pp. 64-74, doi:10.11178/JDSA.6.64.

Ahmad, Faiz, et al. "Genetic Divergence and Heritability of 42 Coloured Upland Rice Genotypes (Oryzasativa) as Revealed by Microsatellites Marker and Agro-Morphological Traits." PLOS ONE, vol. 10, no. 9, Public Library of Science, Sept. 2015, p. e0138246, doi:10.1371/JOURNAL.PONE.0138246.

Ahmadizadeh, Mostafa, and Hamed Felenji. "Evaluating Diversity among Potato Cultivars Using Agro-Morphological and Yield Components in Fall Cultivation of Evaluating Diversity among Potato Cultivars Using Agro-Morphological and Yield Components in Fall Cultivation of Jiroft Area." J. Agric. \& Environ. Sci, vol. 11, no. 5, 2011, pp. 655-62.

Akinwale, M. G., et al. "Heritability and Correlation Coefficient Analysis for Yield and Its Components in Rice (Oryza Sativa L.)." African Journal of Plant Science, vol. 5, no. 3, Academic Journals, Mar. 2011, pp. 207-12, doi:10.5897/AJPS.9000137.

Amin, Ruhul, et al. Assessment of Genetic Response and Character Association for Yield and Yield Components in Lentil (Lens Culinaris L.) Population Developed through Chemical Mutagenesis under a Creative Commons Attribution (CC-BY) 4.0 License. 2015, doi:10.1080/23311932.2014.1000715.

Beaumont, Mark A., et al. "Measuring Genetic Distance.” Molecular Tools for Screening Biodiversity, Springer, Dordrecht, 1998, pp. 315-25, doi:10.1007/978-94-009-0019-6_58.

Bhattacharya, A., et al. "Antioxidant Constituents and Enzyme Activities in Chilli Peppers." Http://Dx.Doi.Org/10.1080/19315260903529709, vol. 16, no. 3, Taylor \& Francis Group, July 2010, pp. 201-11, doi:10.1080/19315260903529709.

Burton, Glenn W., and E. H. DeVane. "Estimating Heritability in Tall Fescue (Festuca Arundinacea) from Replicated Clonal Material1." Agronomy Journal, vol. 45, no. 10, John Wiley \& Sons, Ltd, Oct. 1953, pp. 478-81, doi:10.2134/AGRONJ1953.00021962004500100005X.

Caillei, Abelmoschus, et al. "Comparative Analysis of Genotype x Environment Interaction Techniques in West African Okra.” Journal of Agricultural Science, vol. 4, no. 4, 2012, doi:10.5539/jas.v4n4p135.

Choudhary, Arbind K., et al. "Integrated Physiological and Molecular Approaches to Improvement of Abiotic Stress Tolerance in Two Pulse Crops of the Semi-Arid Tropics." The Crop Journal, vol. 6, no. 2, Elsevier, Apr. 2018, pp. 99-114, doi:10.1016/J.CJ.2017.11.002.

Craufurd, P. Q., and T. R. Wheeler. "Climate Change and the Flowering Time of Annual Crops." Journal of Experimental Botany, vol. 60, no. 9, Oxford Academic, July 2009, pp. 2529-39, doi:10.1093/JXB/ERP196.

Datta, S., and J. C. Jana. "Influence of Different Sources of Phosphorus and Phosphate Solubilizing Bacteria on Productivity of Rainfed Rice ( Oryza Sativa L.)." Journal of Crop and Weed, vol. 7, no. 1, 2011, pp. 44-48.

De Haro-Bailón, A., and M. Del Rio. "Isolation of Chemically Induced Mutants in Borage (Borago Officinalis L.)." Journal of the American Oil Chemists' Society 1998 75:2, vol. 75, no. 2, Springer, 1998, pp. 281-83, doi:10.1007/S11746-998-0042-7. 
Dela, Gal, et al. "Changes in Anthocyanin Concentration and Composition in 'Jaguar' Rose Flowers Due to Transient High-Temperature Conditions.” Plant Science, vol. 164, no. 3, Elsevier, Mar. 2003, pp. 333-40, doi:10.1016/S0168-9452(02)00417-X.

Devi, A. Sri, and L. Mullainathan. "Effect of Gamma Rays and Ethyl Methane Sulphonate (EMS) in $\mathrm{M}_{3}$ Generation of Blackgram (Vigna Mungo L. Hepper)." African Journal of Biotechnology, vol. 11, no. 15, Feb. 2014, pp. 3548-52, doi:10.4314/ajb.v11i15.

Fechtali, Mohamed El, and Abdelghani Nabloussi. Development and Evaluation of Diverse Promising Rapeseed (Brassica Napus L.) Mutants Using Physical and Chemical Mutagens. 2019.

Gatti, Ileana, et al. Heritability and Expected Selection Response for Yield Traits in Blanched Asparagus. https://www.researchgate.net/publication/7896884. Accessed 22 Aug. 2021.

Kaushik, N., et al. "Genetic Variation and Heritability Estimation in Jatropha Curcas L. Progenies for Seed Yield and Vegetative Traits." Journal of Applied and Natural Science, vol. 7, no. 2, ANSF Publications, Dec. 2015, pp. 567-73, doi:10.31018/JANS.V7I2.646.

Kumar, Nitish, et al. Estimation of Genetic Variability in Bell Pepper (Capsicum Annuum L. Var. Grossum) Studies on Genetic Divergence in Bell Pepper Capsicum Annum L. Var. Grossum View Project Despatch Tools Used in Decision Support System View Project. 2019, https://www.researchgate.net/publication/335227817.

Laskar, Rafiul Amin, and Samiullah Khan. Assessment on Induced Genetic Variability and Divergence in the Mutagenized Lentil Populations of Microsperma and Macrosperma Cultivars Developed Using Physical and Chemical Mutagenesis. no. September, 2017, doi:10.1371/journal.pone.0184598.

Mahajan, Reetika, et al. "Assessment of Genetic Variability, Heritability and Genetic Advance among Pisum Accessions." Article in International Journal of Plant Research, 2017, doi:10.5958/2229-4473.2017.00125.2.

Malek, M. A., et al. "Morphological Characterization and Assessment of Genetic Variability, Character Association, and Divergence in Soybean Mutants." Scientific World Journal, vol. 2014, Hindawi Publishing Corporation, 2014, doi:10.1155/2014/968796.

MISHRA, PRANAV KUMAR, et al. "Genetic Variability, Heritability, and Genetic Advance in Strawberry(Fragaria × Ananassa Duch.)." TURKISH JOURNAL OF AGRICULTURE AND FORESTRY, vol. 39, no. 3, The Scientific and Technological Research Council of Turkey, June 2015, pp. 451-58, http://journals.tubitak.gov.tr/agriculture/.

Mishra, T. S., et al. " Performance of Different Genotypes of Chilli ( Capsicum Annum ) under Allahabad Agro-Climatic Condition ." Journal of Krishi Vigyan, vol. 6, no. 1, Diva Enterprises Private Limited, 2017, p. 141, doi:10.5958/2349-4433.2017.00066.6.

Muduli, K. C., and R. C. Misra. Induced Polygenic Variability in M2 Generation and Its Relationship with Production of High-Yielding Mutants in Finger Millet. 2008, http://www.indianjournals.com/ijor.aspx?target $=$ ijor:ijgpb\&volume $=68 \&$ issue $=4 \&$ article $=0$ $11 \&$ type $=$ pdf.

Najeeb, S., et al. "Studies on Genetic Variability, Genotypic Correlation and Path Coefficient Analysis in Maize under the High Altitude Temperate Conditions of Kashmir." Maize Genetics Cooperation Newsletter, no. No.83, Maize Genetics Executive Committee (MGEC), 2009.

Nishihara, Masahiro, and Takashi Nakatsuka. "Genetic Engineering of Flavonoid Pigments to Modify Flower Color in Floricultural Plants.” Biotechnology Letters 2010 33:3, vol. 33, no. 3, Springer, Nov. 2010, pp. 433-41, doi:10.1007/S10529-010-0461-Z. 
O., Afuape S., et al. "Multivariate Assessment of the Agromorphological Variability and Yield Components among Sweet Potato (Ipomoea Batatas (L.) Lam) Landraces." African Journal of Plant Science, vol. 5, no. 2, Academic Journals, Feb. 2011, pp. 123-32, doi:10.5897/AJPS.9000176.

Ogunniyan, D. J., and S. A. Olakojo. "Genetic Variation, Heritability, Genetic Advance and Agronomic Character Association of Yellow Elite Inbred Lines of Maize (Zea Mays L.)." Nigerian Journal of Genetics, vol. 28, no. 2, No longer published by Elsevier, July 2014, pp. 24-28, doi:10.1016/J.NIGJG.2015.06.005.

Oladosu, Yusuff, et al. "Principle and Application of Plant Mutagenesis in Crop Improvement: A Review." Http://Mc.Manuscriptcentral.Com/Tbeq, vol. 30, no. 1, Taylor \& Francis, 2015, pp. 1-16, doi:10.1080/13102818.2015.1087333.

OSMAN, KHALID A., et al. "Genetic Variability for Yield and Related Attributes of Upland Rice Genotypes in Semi Arid Zone (Sudan)." African Journal of Agricultural Research, vol. 7, no. 33, Academic Journals, Aug. 2012, pp. 4613-19, doi:10.5897/AJAR12.529.

Osuna-García, Jorge A., et al. Endogenous Levels of Tocopherols and Ascorbic Acid during Fruit Ripening of New Mexican-Type Chile (Capsicum Annuum L.) Cultivars. 1998, doi:10.1021/jf980588h.

Raturi, Aparna, et al. "Genetic Variability, Heritability, Genetic Advance and Path Analysis in Mungbean [Vigna Radiata (L.) Wilczek].” Legume Research, vol. 38, no. 2, Agricultural Research Communication Centre, Apr. 2015, pp. 157-63, doi:10.5958/09760571.2015.00024.7.

Robertson, Alan. "The Sampling Variance of the Genetic Correlation Coefficient." Biometrics, vol. 15, no. 3, JSTOR, Sept. 1959, p. 469, doi:10.2307/2527750.

Saha, SR, et al. "Effect of High Temperature Stress on the Performance of Twelve Sweet Pepper Genotypes." Bangladesh Journal of Agricultural Research, vol. 35, no. 3, Bangladesh Journals Online (JOL), Jan. 2010, pp. 525-34, doi:10.3329/BJAR.V35I3.6459.

Sakai, Kan Ichi, and Akio Suzuki. "Induced Mutation and Pleiotropy of Genes Responsible for Quantitative Characters in Rice." Radiation Botany, vol. 4, no. 2, Pergamon, Jan. 1964, pp. 141-51, doi:10.1016/S0033-7560(64)80065-X.

Sood, Sonia, et al. "Genetic Variation and Association Analysis for Fruit Yield, Agronomic and Quality Characters in Bell Pepper.” Http://Dx.Doi.Org/10.1080/19315260902875822, vol. 15, no. 3, Taylor \& Francis Group , July 2009, pp. 272-84, doi:10.1080/19315260902875822.

SURPRENANT, J., et al. "HERITABILITY OF PHYSICAL PROPERTIES AND OTHER QUALITY TRAITS IN TIMOTHY.” Https://Doi.Org/10.4141/Cjps90-084, vol. 70, no. 3, NRC Research Press Ottawa, Canada, July 2011, pp. 683-89, doi:10.4141/CJPS90-084.

Thirumala Rao, V. "Genetic Variability, Correlation and Path Coefficient Analysis under Drought in Groundnut (Arachis Hypogaea L.)." Legume Research, vol. 39, no. 2, Agricultural Research Communication Centre, Apr. 2016, pp. 319-22, doi:10.18805/LR.V39I2.9536.

Tuhina-Khatun, Mst, et al. "Genetic Variation, Heritability, and Diversity Analysis of Upland Rice (Oryza Sativa L.) Genotypes Based on Quantitative Traits.” BioMed Research International, vol. 2015, Hindawi Publishing Corporation, 2015, doi:10.1155/2015/290861.

Ullah, M. Z., et al. "GENETIC VARIABILITY AND CORRELATION IN EXOTIC CUCUMBER (Cucumis Sativus L.) VARIETIES.” Bangladesh Journal of Plant Breeding and Genetics, vol. 25, no. 1, Bangladesh Journals Online (JOL), June 2012, pp. 17-23, 
doi:10.3329/BJPBG.V25I1.17008.

Usman, Magaji G., et al. "Capsaicin and Dihydrocapsaicin Determination in Chili Pepper Genotypes Using Ultra-Fast Liquid Chromatography." Molecules 2014, Vol. 19, Pages 6474-6488, vol. 19, no. 5, Multidisciplinary Digital Publishing Institute, May 2014, pp. 6474-88, doi:10.3390/MOLECULES19056474.

Vanitha, SM, et al. Vegetable Statistics. no. 7, ICAR-IIVR, Mar. 2013, http://krishi.icar.gov.in/jspui/handle/123456789/47775.

"Vegetable Production and Practices." Vegetable Production and Practices, CABI, 2015, doi:10.1079/9781780645346.0000.

Zaman, MA, et al. "Genetic Variability and Path Analysis of Groundnut (Arachis Hypogaea L.)." The Agriculturists, vol. 9, no. 1-2, Bangladesh Journals Online (JOL), Jan. 2011, pp. 29-36, doi:10.3329/AGRIC.V9I1-2.9476. 


\section{Figures}
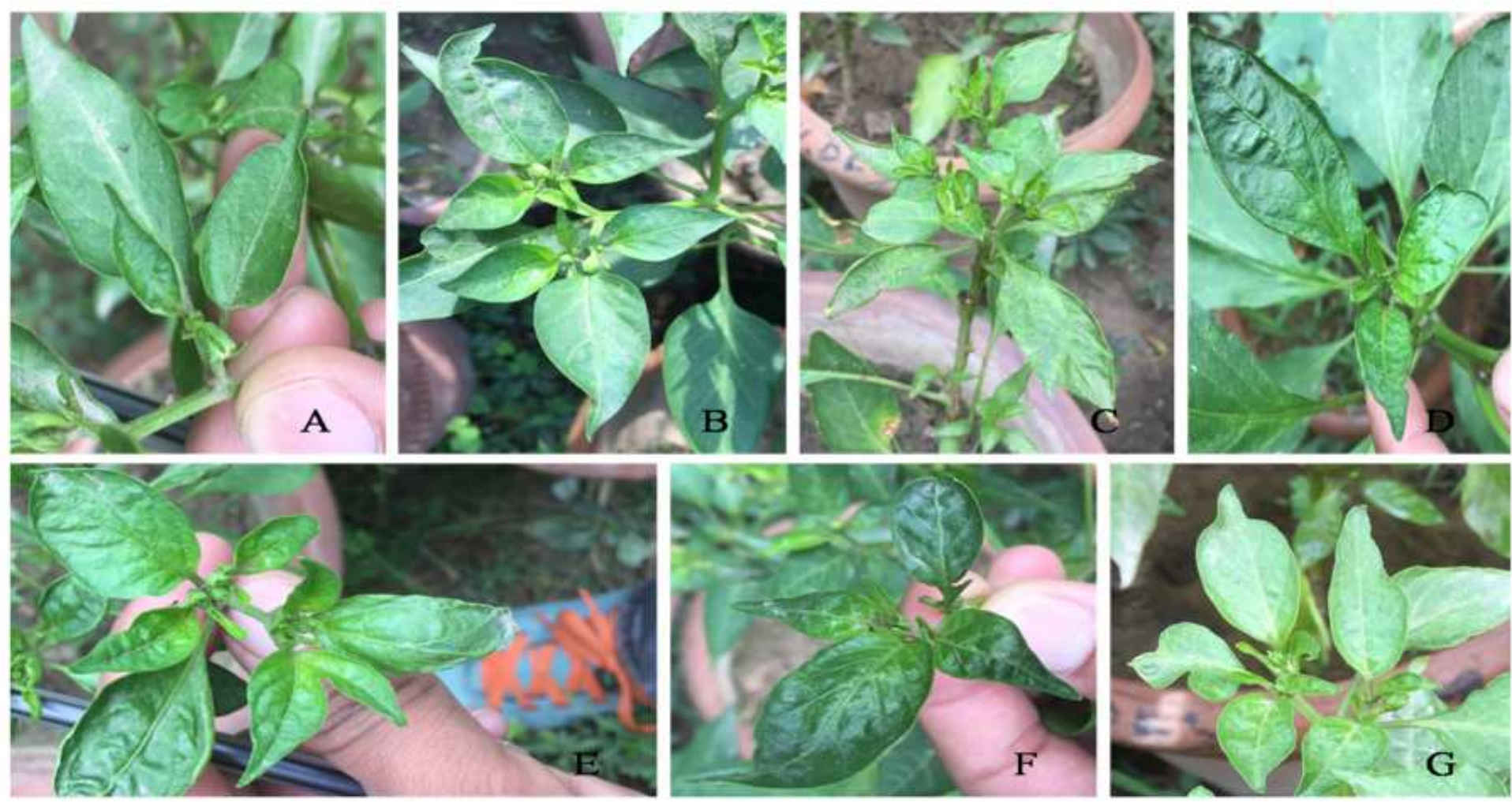

\section{Figure 1}

Morphological mutations (Plant with altered leaf morphology). A: ovate, B: Tip curve leaf, C: Normal leaf, D: Curly rectangular leaf, E: Bilobed leaf, F: Oval leaf, G: Notched leaf. 


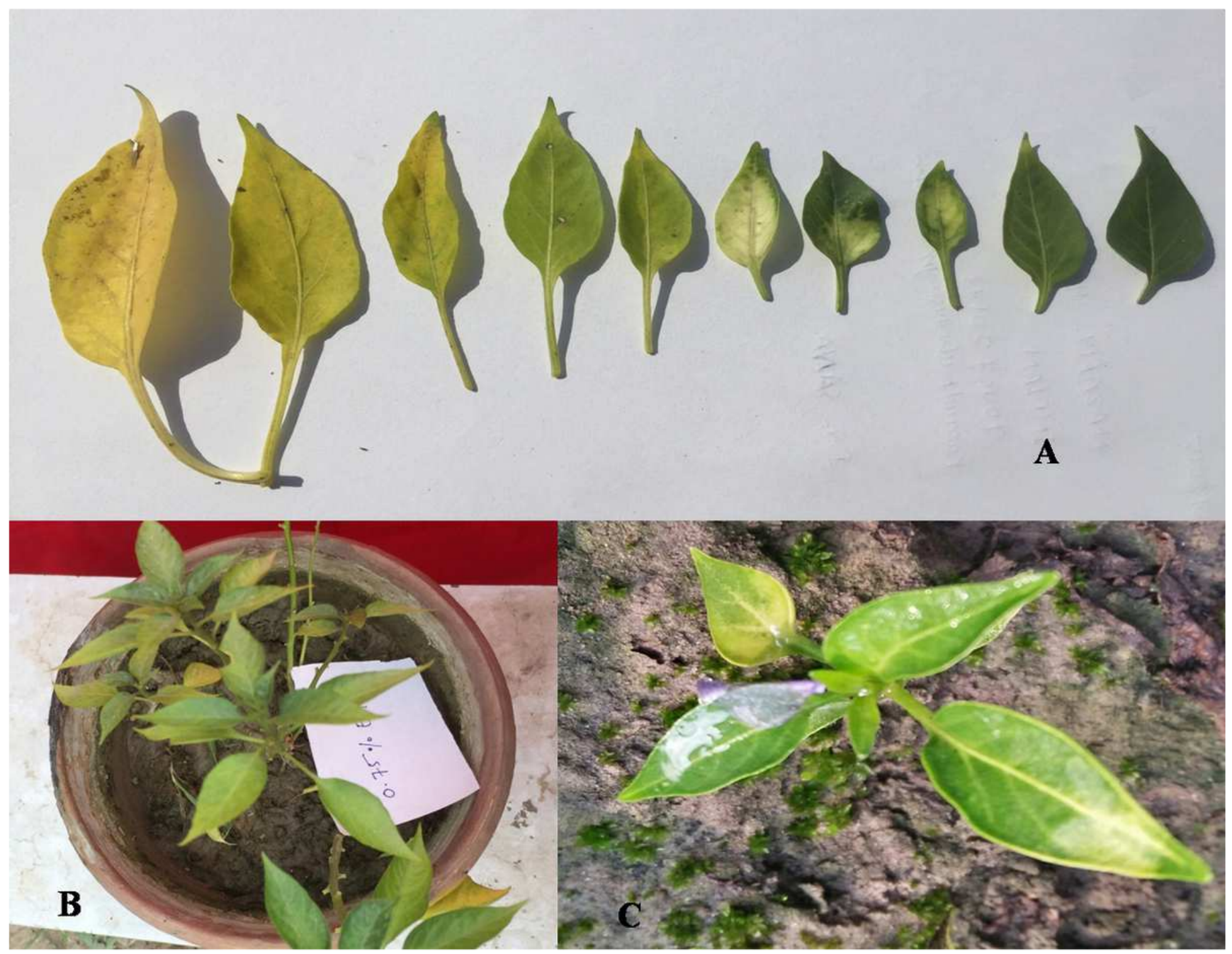

Figure 2

Morphological mutations (leaf with chlorophyll variations) A: Light yellow to dark green leaves, B: Aurea leaf, C: Viridis leaf 

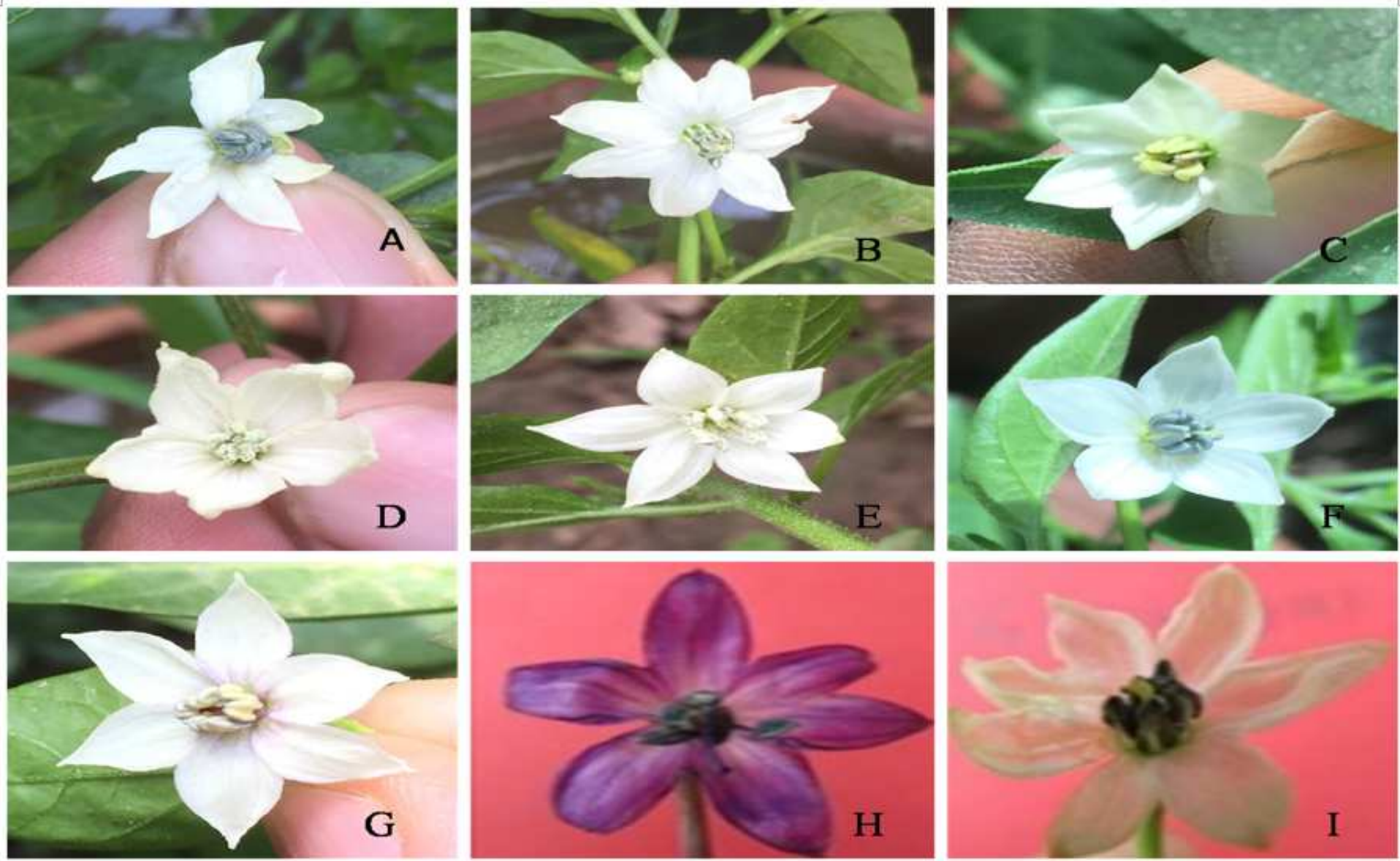

\section{Figure 3}

Morphological mutations (flower with color and shape variation). A: Two small and four large petals with purple anther, B: Eight petals and white anther, C: Joint petals and yellow anther, D: Curly petals, E:

Embricate petals, F: Light blue petals with light blue anther, G: Pink base embricate petals, H: Violet petals with violet anther, I: Light whitish petals with black anthers. 


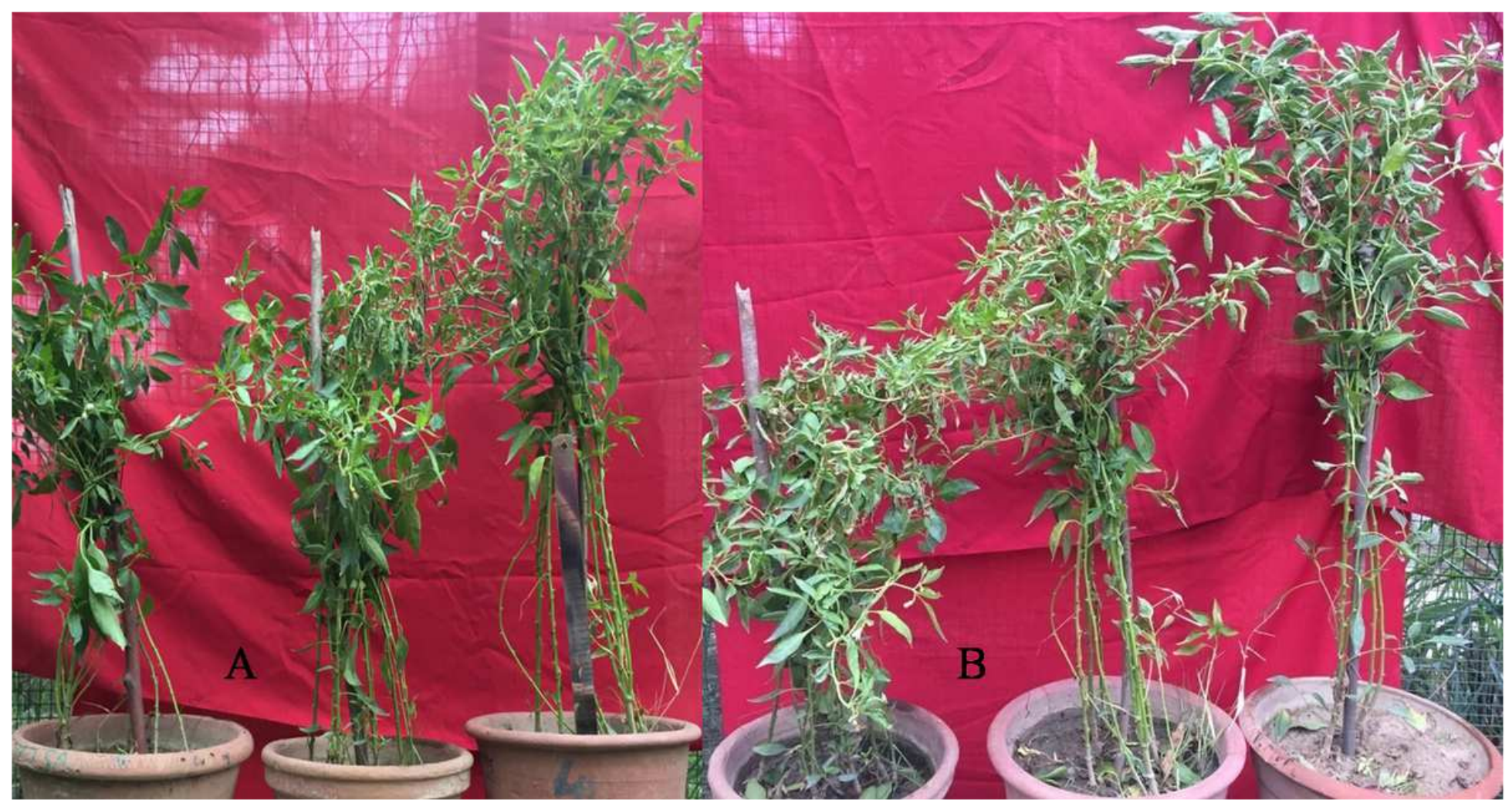

\section{Figure 4}

Morphological mutations (plant with altered height and growth habit). A: Tall and dwarf plants with more branches, B: Tall and dwarf plants with low branches 


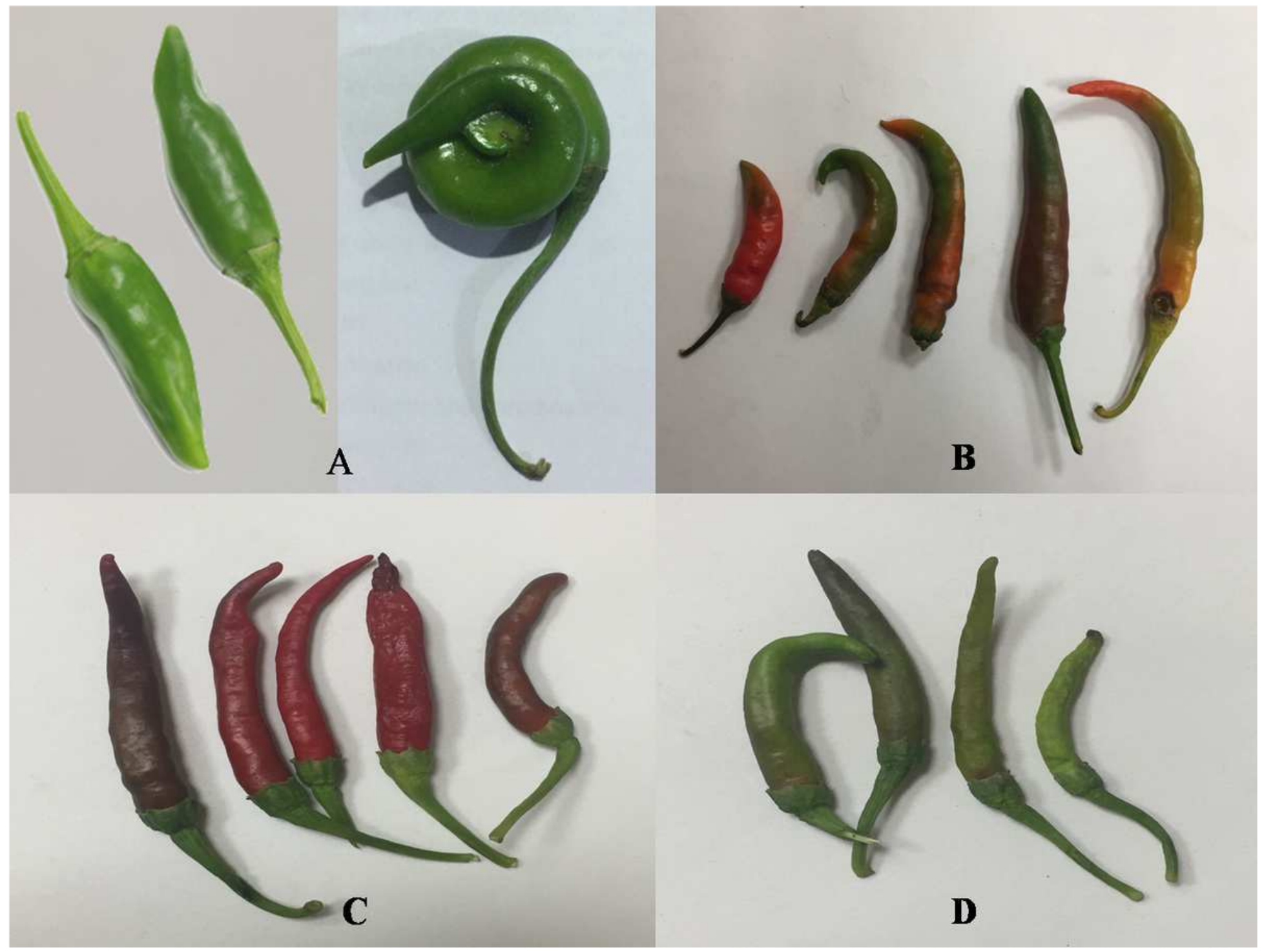

Figure 5

Morphological mutation (fruits with color and shape variations). A: Light green, small and rounded curve fruit, B: Pale reddish to light red fruits, C: Dark red and black fruit, D: Dark green fruits. 


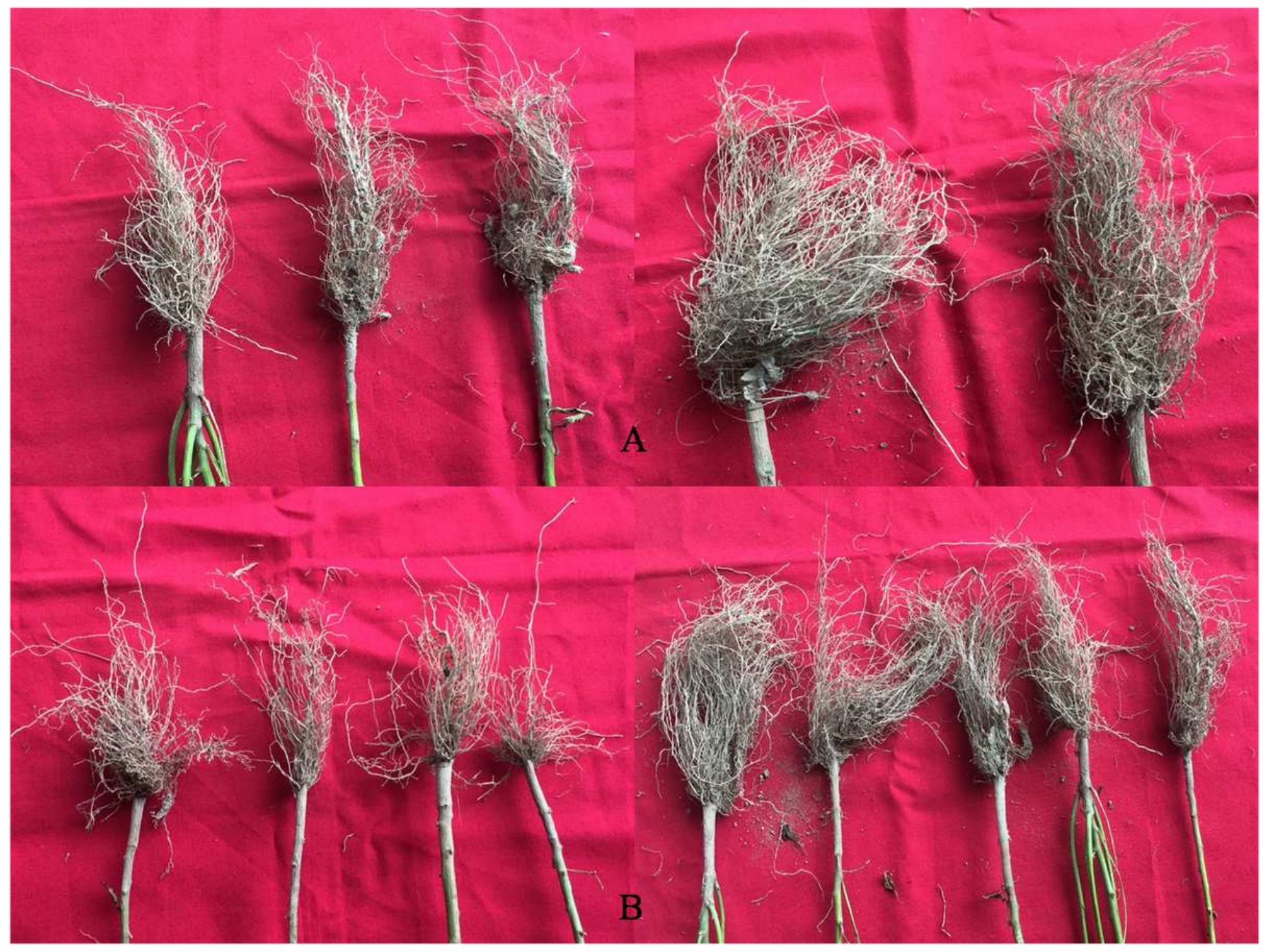

Figure 6

Morphological mutations (roots with fibers variations). A: Long and highly fibrous roots, B: Small and less Fibrous root 
Dendrogram Using Ward Method

Rescaled Distance Clnster Combine

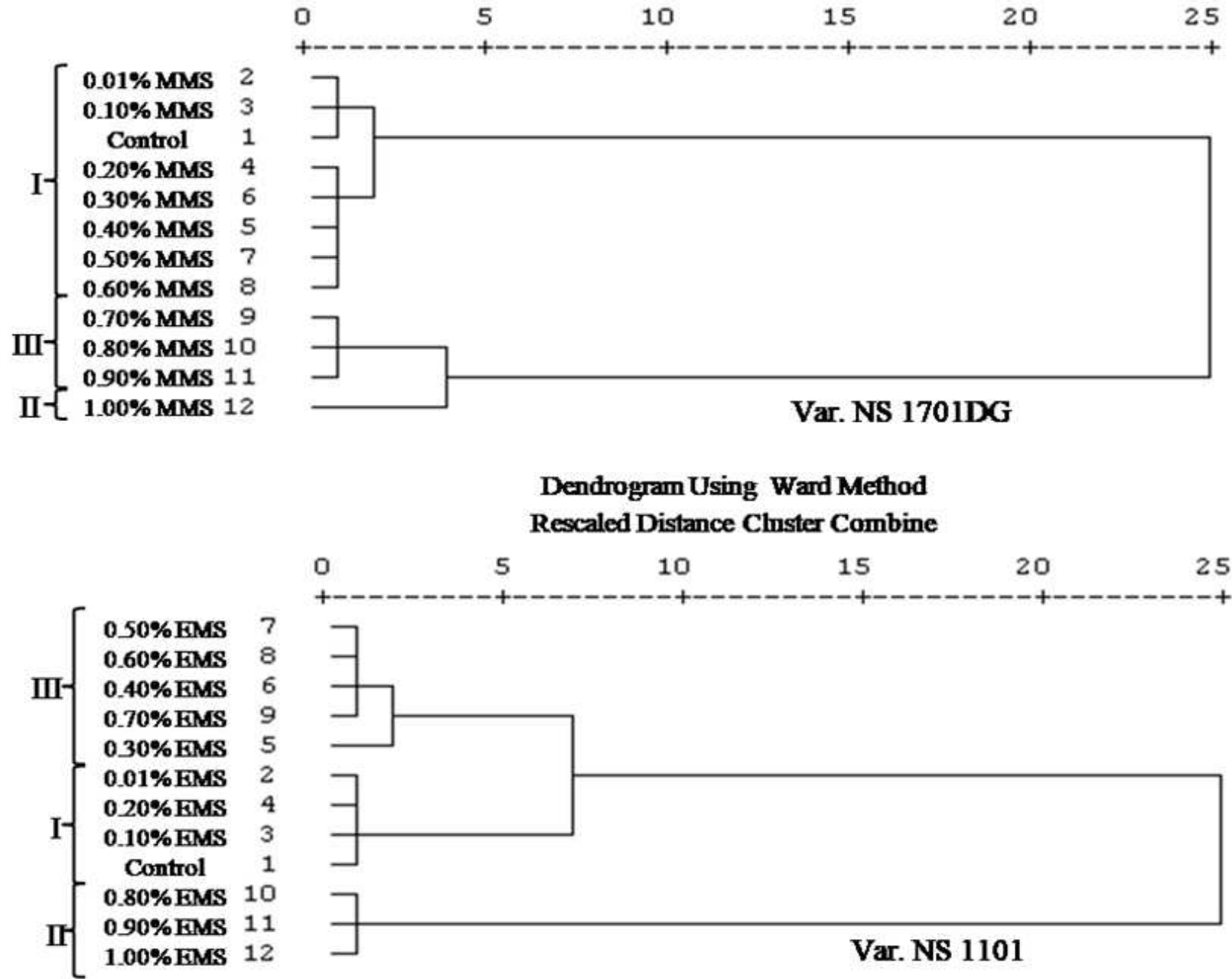

\section{Figure 7}

Dendrograms of chilli cultivars population clustering based on nine quantitative traits. 